\title{
Determinants of Hip and Femoral Deformities in Children With Spastic Cerebral Palsy
}

\author{
Yoona Cho, MD, Eun Sook Park, MD, PhD, Han Kyul Park, MD, \\ Jae Eun Park, MD, Dong-wook Rha, MD, PhD \\ Department of Rehabilitation Medicine and Research Institute of Rehabilitation Medicine, \\ Yonsei University College of Medicine, Seoul, Korea
}

Objective To find factors affecting hip and femoral deformities in children with spastic cerebral palsy (CP) by comparing various clinical findings with imaging studies including plain radiography and computed tomography (CT) imaging.

Methods Medical records of 709 children with spastic CP who underwent thorough baseline physical examination and functional assessment between 2 to 6 years old were retrospectively reviewed. Fifty-seven children (31 boys and 26 girls) who had both plain radiography of the hip and three-dimensional CT of the lower extremities at least 5 years after baseline examination were included in this study.

Results The mean age at physical examination was 3.6 years ( $\mathrm{SD}=1.6$; range, $2-5.2$ years) and the duration of follow-up imaging after baseline examination was 68.4 months ( $\mathrm{SD}=22.0$; range, 60-124 months). The migration percentage correlated with motor impairment and the severity of hip adductor spasticity (R1 angle of hip abduction with knee flexion). The femoral neck and shaft angle correlated with the ambulation ability and severity of hip adductor spasticity (R1 and R2 angles of hip abduction with both knee flexion and extension).

Conclusion Hip subluxation and coxa valga deformity correlated with both dynamic spasticity and shortening of hip adductor muscles. However, we found no correlation between femoral deformities such as femoral anteversion, coxa valga, and hip subluxation.

Keywords Cerebral palsy, Coxa valga, Hip dislocation, Bone anteversion, Muscle spasticity

\section{INTRODUCTION}

Hip displacement and dislocation are common in children with cerebral palsy (CP) and are known to cause hip pain, severe contractures, windswept deformity, and motor disability [1-3]. Abnormal forces created by hip adductor muscles, followed by the influence of the hamstrings and iliopsoas have been suggested as the etiology

Received May 24, 2017; Accepted July 20, 2017

Corresponding author: Dong-wook Rha

Department of Rehabilitation Medicine and Research Institute of Rehabilitation Medicine, Yonsei University College of Medicine, 50-1 Yonsei-ro Seodaemun-gu, Seoul 03722, Korea. Tel: +82-2-2228-3717, Fax: +82-2-363-2795, E-mail: MEDICUS@yuhs.ac

ORCID: Yoona Cho (http://orcid.org/0000-0002-8792-5828); Eun Sook Park (http://orcid.org/0000-0002-9144-3063); Han Kyul Park (http://orcid. org/0000-0002-6695-9156); Jae Eun Park (http://orcid.org/0000-0001-8790-7681); Dong-wook Rha (http://orcid.org/0000-0002-7153-4937).

(c) This is an open-access article distributed under the terms of the Creative Commons Attribution Non-Commercial License (http://creativecommons.org/ licenses/by-nc/4.0) which permits unrestricted noncommercial use, distribution, and reproduction in any medium, provided the original work is properly cited. Copyright (C) 2018 by Korean Academy of Rehabilitation Medicine 
of hip displacement [4]. It has been thought that these abnormal forces induced various abnormal deformities of the hip and femur such as excessive femoral anteversion and coxa valga, which resulted in hip displacement and dislocation. However, controversial results were also reported $[1,4,5]$.

Femoral anteversion is defined as an anterior projection of the femoral head and neck relative to a plane in the femur in line with the femoral knee joint axis [4]. The range of femoral anteversion is $30^{\circ}-40^{\circ}$ at birth, which progressively decreases throughout growth to $15^{\circ}$ by 16 years of age $[6,7]$. Children with spastic CP often show excessive femoral anteversion, however, the etiology is not clear. Some previous studies reported that at the functional level, fetal alignment and hip adductor spasticity could affect femoral anteversion in children with CP $[6,7]$.

Coxa valga is an anatomical deformity where the femoral neck and shaft angle (FNS) exceeds normal limits; it has no recognizable cause or mechanism that can be assessed during physical examination. The FNS of infants is normally about $150^{\circ}$. With the influence of abductor force and walking, this gradually decreases to the normal adult range of $115^{\circ}$ to $120^{\circ}$ by 8 years of age. Most of this correction actually occurs by 2 to 3 years of age. However, many children with $\mathrm{CP}$ have some degree of coxa valga, which can be as severe as $180^{\circ}$, with $150^{\circ}$ to $160^{\circ}$ being relatively common in children with severe spasticity and the inability to bear weight [8]. Although this form of coxa valga has been attributed to spastic hip subluxation and dislocation, the current understanding is based on analyses of multiple factors rather than the etiology of dislocation [4].

Risk factors causing excessive femoral anteversion, coxa valga, and consequential hip subluxation have been reported rarely. Muscle spasticity, joint contractures, and functional impairments have been suggested as associated factors [9-11].

The aim of this study was to determine factors affecting hip and femoral deformities of children with spastic $\mathrm{CP}$ by comparing various clinical findings with imaging studies taken at least 5 years after baseline examination.

\section{MATERIALS AND METHODS}

Medical records of 709 children between 2 to 6 years old with CP who underwent thorough baseline physical examination and functional assessment as part of a prebotulinum toxin injection evaluation were retrospectively reviewed (from 2005 to 2011). Ethical approval was granted by the Institutional Review Board (No. 4-20170167) and Ethics Committee of Severance Hospital. Of
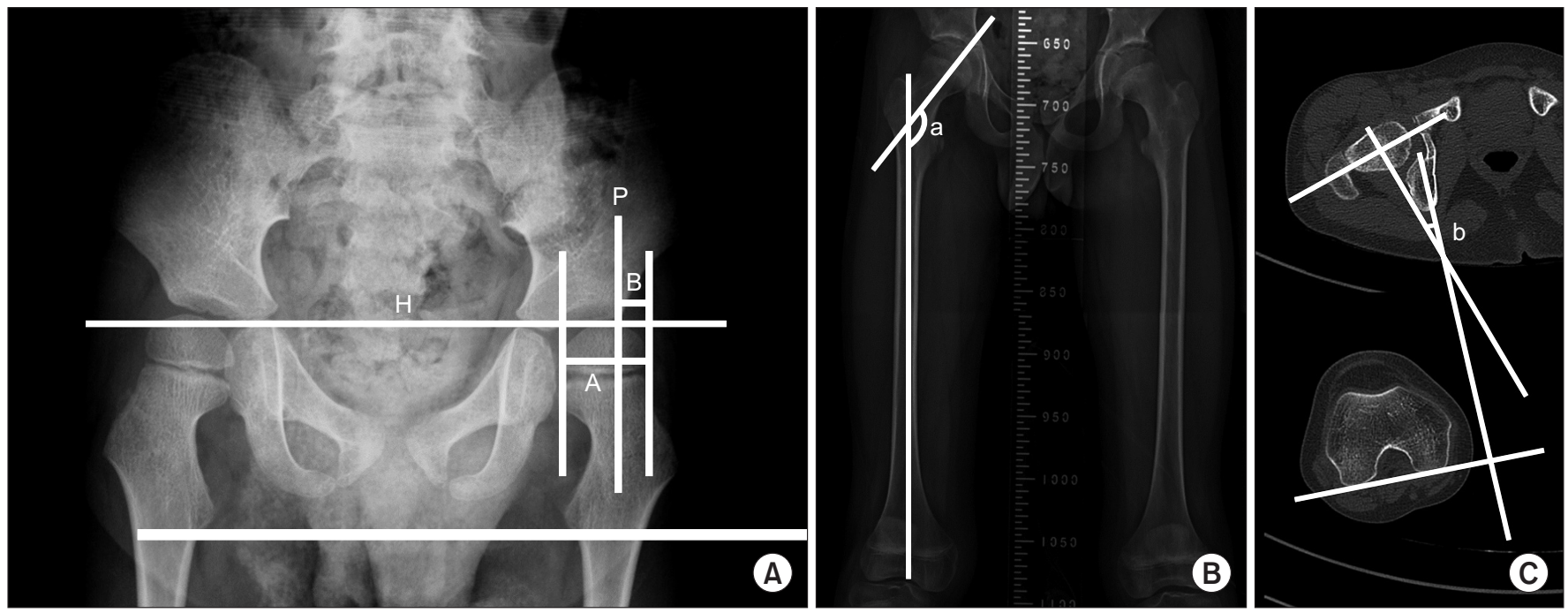

Fig. 1. (A) Measurement of migration percentage (MP). MP=B/A×100. Hilgenreiner's line and Perkins line are marked as ' $\mathrm{H}$ ' and ' $\mathrm{P}$. $\mathrm{MP}$ is the proportion (\%) of the capital epiphysis that appears to lie outside the acetabulum. (B) Measurement of the femoral neck and shaft angle (FNS). ' $a$ ' is the FNS measurement, performed in standard anterior-posterior X-rays of the proximal femur or pelvis, which was generated by the intersection angle between the femoral neck axis and femoral shaft axis. (C) Measurement of femoral anteversion, ' $b$ ' shows that the femoral anteversion is defined by the angle created by femoral neck axis and posterior condylar axis. 
these, 60 children underwent three-dimensional computed tomography (3D CT) of the lower extremities and plain radiography of the hip at least 5 years after baseline examination as a pre-operative evaluation for orthopaedic surgery. Two children with additional dyskinetic features and one child without adequate imaging studies were excluded. Fifty-seven children ( 31 boys and 26 girls) who had undergone 3D CT of the lower extremities and plain radiography of the hip minimum 60 to maximum 124 months after baseline examination were included in this study. According to the Gross Motor Function Classification System (GMFCS), we classified children into the community ambulatory group (GMFCS I and II) and the non-community ambulatory group (GMFCS III-V). We selected the affected side for unilateral $\mathrm{CP}$ and the more spastic side, which means less angle of R1 of Modified Tardieu Scale (MTS), for bilateral CP.

Spasticity was measured using the MTS, which was developed by Tardieu et al. [12] in 1954 and later modified by Boyd and Graham [13]. Two angles of hip abduction with knee flexion and extension were measured after slow and fast stretches of the hip adductor muscles, referred to as R2 and R1 angles, respectively. Popliteal angles were also measured after slow and fast stretches of the hamstring muscles. $\mathrm{R} 1$ was assessed at the angle of each joint where a catch was first felt during a quick stretch of the joint. R2 was the passive range of motion at each joint [6].

The migration percentage (MP) and the FNS were measured from the anterior-posterior view of the radiograph (Fig. 1A, 1B). Femoral anteversion (FA) was measured from the 3D CT [4] (Fig. 1C). All measurements were performed by one of the authors (Y. Cho) to eliminate inter-rater variability [4]. Intra-rater reliability of hip and femoral deformity parameters are intraclass correlation coefficient (ICC) 0.96, 0.95, and 0.96 for MP, FNS, and FA.

\section{Statistical analyses}

We compared the deformity parameters between clinical groups using Student t-test. In addition, we correlated clinical findings and radiologic deformity parameters using Pearson correlation. We used univariate linear regression to assess the relationship between clinical findings and radiologic deformity parameters. Also we calculated ICC to establish intra-rater reliability. Statistical analyses were performed using R v3.3.1 (R Foundation for Statistical Computing, http://www.R-project.org). A p-value of $<0.01$ was defined as statistically significant.

\section{RESULTS}

The demographic and baseline characteristics of the study population are shown in Table 1. Mean age at the time of baseline physical examination was 3.6 years (range, 2-6 years) and mean follow-up after baseline physical examination for imaging studies was 68.4 months ( $\mathrm{SD}=22.0$; range, 60-124 months). The percentage (number) of patients in GMFCS level I was $35.1 \%(n=20)$, level II was $22.8 \%$ ( $n=13)$, level III was $17.5 \%(n=10)$, level IV was

Table 1. Characteristics of participants ( $\mathrm{n}=57)$

\begin{tabular}{lc}
\hline \multicolumn{1}{c}{ Characteristic } & Value \\
\hline Age (yr) & $3.6 \pm 1.6(2-6)$ \\
\hline At P/Ex & $9.3 \pm 1.8(7-14)$ \\
\hline At imaging study & $68.8 \pm 22.0(60-124)$ \\
\hline $\begin{array}{l}\text { Duration between P/Ex and } \\
\text { imaging study (mo) }\end{array}$ & \\
\hline Sex & \\
\hline Male & $31(54.4)$ \\
\hline Female & $26(45.6)$ \\
\hline Body involvement & \\
\hline Unilateral & $10(17.5)$ \\
\hline Bilateral & $47(82.5)$ \\
\hline GMFCS level at P/Ex & \\
\hline I & $20(35.1)$ \\
\hline II & $13(22.8)$ \\
\hline III & $10(17.5)$ \\
\hline IV & $11(19.3)$ \\
\hline V & $3(5.3)$ \\
\hline Popliteal angle $\left({ }^{\circ}\right)$ & \\
\hline R1 of MTS & $52.5 \pm 23.7$ \\
\hline R2 of MTS & $23.3 \pm 17.1$ \\
\hline Hip abduction with knee extension $\left(^{\circ}\right)$ \\
\hline R1 of MTS & $26.9 \pm 17.1$ \\
\hline R2 of MTS & $37.4 \pm 14.4$ \\
\hline Hip abduction with knee flexion $\left(^{\circ}\right)$ & \\
\hline R1 of MTS & $44.9 \pm 17.7$ \\
\hline R2 of MTS & $63.4 \pm 11.2$ \\
\hline Femoral neck and shaft angle $\left(^{\circ}\right)$ & $28.8 \pm 17.9$ \\
\hline Femoral anteversion $\left(^{\circ}\right)$ & $26.1 \pm 12.6$ \\
\hline
\end{tabular}

Values are expressed as mean \pm standard deviation (range) or number of participants (\%).

P/Ex, physical examination; GMFCS, Gross Motor Functional Classification System; MTS, Modified Tardieu Scale. 
$19.3 \%(\mathrm{n}=11)$, and level $\mathrm{V}$ was $5.3 \%(\mathrm{n}=3)$.

The MP was significantly higher in bilateral CP compared to unilateral CP. The FNS was significantly larger in the non-community ambulatory group compared to the community ambulatory group ( $\mathrm{p}<0.01)$ (Table 2$)$.

The MP was inversely correlated with the $\mathrm{R} 1$ angle of hip abduction with knee flexion (coefficient $=-0.378$, $\mathrm{p}<0.01$ ) (Table 3). The FNS was also inversely correlated with all hip abduction angles regardless of knee flexion or extension. However, there was no correlation between spasticity of the hip adductor muscles and FA. Furthermore, spasticity of hamstring muscles was not correlated with any radiologic parameter.

We analyzed the relationship between clinical findings and radiologic hip and femoral deformity parameters using univariate linear regression (Table 4). The noncommunity ambulatory group had larger MP ( $\beta$ coef- ficient $=15.83, p=0.003)$ and FNS $(\beta$ coefficient $=7.07$, $\mathrm{p}=0.001$ ) compared to the community ambulatory group. As the R1 angle of hip abduction with knee flexion decreased, the MP increased. However, the R1 angle of hip abduction with knee extension, R2 angles of hip abduction with both knee flexion and extension, and R1 and R2 of popliteal angles were not correlated with the MP. The larger FNS were correlated with smaller R1 and R2 angles of hip abduction regardless of knee position. FA angle was not correlated with any demographic or clinical findings. Finally, there was no correlation between radiologic femoral and hip deformity parameters (Table 5).

\section{DISCUSSION}

Coxa valga has been defined as increased FNS [1416]. Several studies have reported the effects of age and

Table 2. Comparison of radiologic hip and femoral deformity parameters between clinical groups

\begin{tabular}{|c|c|c|c|c|c|c|}
\hline & \multicolumn{2}{|c|}{ Sex } & \multicolumn{2}{|c|}{ Involvement } & \multicolumn{2}{|c|}{ Ambulation at $\mathbf{P} / \mathbf{E x}$} \\
\hline & $\begin{array}{c}\text { Male } \\
(\mathbf{n}=\mathbf{3 1})\end{array}$ & $\begin{array}{c}\text { Female } \\
(n=26)\end{array}$ & $\begin{array}{c}\text { Unilateral } \\
(\mathbf{n}=\mathbf{1 0})\end{array}$ & $\begin{array}{c}\text { Bilateral } \\
(n=47)\end{array}$ & $\begin{array}{c}\text { Community } \\
\text { ambulatory } \\
(n=33)\end{array}$ & $\begin{array}{l}\text { Non-community } \\
\text { ambulatory } \\
(n=24)\end{array}$ \\
\hline Migration percentage (\%) & $26.3 \pm 14.8$ & $31.7 \pm 20.8$ & $18.0 \pm 5.9$ & $31.1^{*} \pm 18.7$ & $25.8 \pm 15.1$ & $32.9 \pm 20.7$ \\
\hline Femoral neck and shaft angle $\left({ }^{\circ}\right)$ & $150.6 \pm 6.9$ & $146.2 \pm 7.4$ & $144.5 \pm 8.6$ & $149.5 \pm 6.9$ & $145.9 \pm 7.0$ & $152.3^{*} \pm 6.4$ \\
\hline Femoral anteversion $\left(^{\circ}\right)$ & $26.6 \pm 13.8$ & $25.6 \pm 11.2$ & $30.5 \pm 10.9$ & $25.2 \pm 12.8$ & $26.2 \pm 11.9$ & $26.0 \pm 13.8$ \\
\hline
\end{tabular}

Values are presented as mean \pm standard deviation.

$\mathrm{P} / \mathrm{Ex}$, physical examination.

${ }^{*} \mathrm{p}<0.01, \mathrm{p}$-value for intergroup comparisons are derived by Student $\mathrm{t}$-test.

Table 3. Correlation between clinical findings at the age of physical examination and radiologic femoral and hip deformity parameters at the age of imaging study

\begin{tabular}{|c|c|c|c|}
\hline & $\begin{array}{c}\text { Migration } \\
\text { percentage }\end{array}$ & $\begin{array}{l}\text { Femoral neck and } \\
\text { shaft angle }\end{array}$ & $\begin{array}{c}\text { Femoral } \\
\text { anteversion }\end{array}$ \\
\hline Age at imaging study & 0.009 & -0.329 & -0.157 \\
\hline \multicolumn{4}{|l|}{ Popliteal angle $\left({ }^{\circ}\right)$} \\
\hline $\mathrm{R} 1$ of MTS & 0.189 & 0.253 & -0.201 \\
\hline R2 of MTS & -0.012 & 0.177 & 0.067 \\
\hline \multicolumn{4}{|c|}{ Hip abduction with knee extension $\left({ }^{\circ}\right)$} \\
\hline R1 of MTS & -0.269 & $-0.447^{*}$ & 0.143 \\
\hline R2 of MTS & -0.124 & $-0.564^{* *}$ & 0.172 \\
\hline \multicolumn{4}{|c|}{ Hip abduction with knee flexion $\left(^{\circ}\right)$} \\
\hline R1 of MTS & $-0.378^{*}$ & $-0.475^{* *}$ & 0.074 \\
\hline R2 of MTS & -0.047 & $-0.364^{*}$ & 0.161 \\
\hline
\end{tabular}

MTS, Modified Tardieu Scale.

${ }^{*} \mathrm{p}<0.01,{ }^{* *} \mathrm{p}<0.001$. 


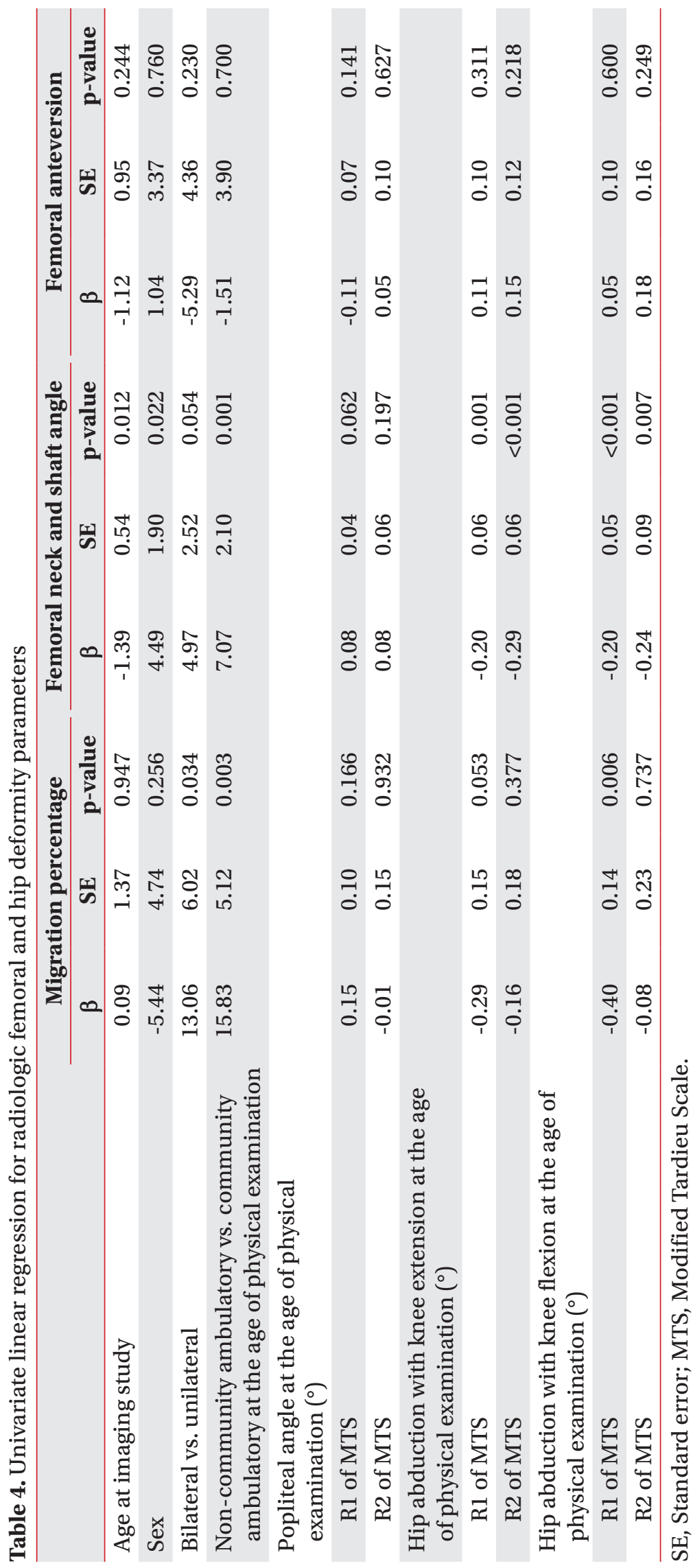


Table 5. Correlation between radiologic femoral and hip deformity parameters

\begin{tabular}{lccc}
\hline & Migration percentage & Femoral neck and shaft angle & Femoral anteversion \\
\hline Migration percentage & - & 0.236 & 0.209 \\
Femoral neck and shaft angle & 0.236 & - & 0.142 \\
Femoral anteversion & 0.209 & 0.142 & - \\
\hline
\end{tabular}

Values are presented as Pearson correlation coefficients between radiologic femoral and hip deformity parameters.

sex on FNS [9-11]. The FNS is largest during childhood and begins to decline during adolescence, slowing further during adulthood. Thus, with advancing age, there would be a minor decline in FNS [9]. Our study reported a similar trend in age, which was lower according to aging $(\mathrm{p}=0.012)$ (Table 4). Although FNS differences according to sex have not been clearly established, it was thought that there was no difference between genders $[9,10]$. However, one study reported that FNS was lower in females [11]. Our study also showed a similar tendency in the coxa valga deformity, which was lower in females ( $\mathrm{p}=0.022$ ) (Table 4$)$.

The FNS was larger in the non-community ambulatory group in our study ( $\mathrm{p}=0.001$ ) (Table 2). This finding agreed with previous reports showing a positive correlation between FNS and GMFCS [16,17]. Although one previous report commented that coxa valga was an acquired deformity according to the functional limitation, the reason why the FNS tended to increase with higher GMFCS level was not clearly established [17]. Therefore, further studies about the mechanism of coxa valga in children with CP should be performed.

FNS is associated with hypertonicity of hip adductor, hamstring, and iliopsoas muscles [14-16]. We used MTS to measure both dynamic spasticity and shortening of hip adductor and hamstring muscles at baseline evaluation. With the MTS, two resulting joint angles can be measured using a goniometer; the Rl angle is the 'angle of catch' after a fast velocity stretch and the R2 angle is the passive joint range of movement following a slow velocity stretch $[6,18]$. Both dynamic spasticity and shortening of hip adductor muscles were significantly correlated with FNS although there was no correlation with hamstring muscles and FNS (Table 3). A linear relationship was found between hip adductor hypertonicity and FNS as well (Table 4). These results implied that reduction of hypertonicity of the hip adductor muscles could prevent the coxa valga deformity. However, further clinical studies are needed to confirm the effect of hypertonicity reduction on coxa valga deformity in children with $\mathrm{CP}$.

FA was usually evaluated by clinical assessment using the trochanteric prominence angle test $[8,17,19]$. However, these clinical methods had limitations in reliability and validity compared to measurement using 3D CT of the lower extremities $[8,17]$. FA is thought to interrupt hip abduction and lead to increased energy consumption during ambulation [19]. It has been thought that hip flexor tightness, imbalance of the hip rotators, weak abductors, and tight hamstring and adductor muscles were the factors affecting FA [19-22]. However, we did not find any correlation between FA and hypertonicity of the hip adductor and hamstring muscles in this study. The excessive hip flexion was thought to increase FA as well [23]. Unfortunately, hip flexor spasticity and tightness were not measured in medical records of this study. Further study is needed to evaluate the effect of hip flexors on FA. Delayed weight bearing was also suggested as the reason for excessive FA $[17,21,24,25]$. Previous studies suggested that non-community ambulatory children with $\mathrm{CP}$ had a larger FA angle compared to community ambulatory children $[7,17,22,26]$. These results were also different from our conclusion ( $\mathrm{p}=0.960$ ) (Table 2 ).

Previous studies of clinical assessment using goniometry and plain radiography to measure FA might have had validity issues and confirmation bias $[20,21]$. Some studies only recruited children with minor motor impairment such as GMFCS level I and II [26], and analyzed all types of CP including dystonic, hypotonic, ataxic, and mixed types [17]. And one hypothesis is many factors can affect in the FA, during aging process, but we examined clinically in young age and follow-up after at least 5 years. Many compounding factors could be influence on FA, but the factors were overlooked. Therefore, factors affecting FA should be studied further.

Hip displacement, which can be quantified by MP, is a common and severe problem in children with $\mathrm{CP}$ and can lead to hip dislocation with joint contracture, pain, and functional impairment [3]. The incidence of hip disloca- 
tion was higher in children with bilateral CP compared to those with unilateral CP [27]. The explanation was that extended upper limb impairment in children with bilateral involvement could raise the risk of hip displacement, and reduced weight bearing could affect the hip deformity in these children as well [27]. Our results showed a similar view where MP was larger in the bilateral involvement group compared to unilateral involvement group $(\mathrm{p}<0.01)$ (Table 2).

MP was greater in the non-community ambulatory group than the community ambulatory group, which meant that gross motor function could affect hip displacement (Table 4). Many previous results confirmed that non-community ambulatory children with severe motor impairment had an increased risk of hip displacement regardless of involvement side [1,28-30]. In addition, GMFCS levels were correlated with risk of hip displacement $[3,31]$.

The spasticity of hip adductor muscles is also an important factor for hip displacement in children with CP [4,7,32-34]. Only the R1 angle of hip abduction with knee flexion, which reflected the spasticity of one-joint hip adductor muscles, correlated with MP in this study (Table 3). A linear relationship was also shown (Table 4).

Humans have several hip adductor muscles, including one-joint and two-joint muscles. One-joint muscles comprise the adductor longus and brevis, while twojoint muscles comprise the gracilis and adductor magnus muscles $[7,33,34]$. During physical examination, we assessed hip spasticity with both knee flexion and extension. If there is no difference in spasticity with knee flexion and extension, one-joint muscles have more influence on spasticity. However, if hip adductor spasticity is more severe in knee extension, then two-joint muscles have more influence on spasticity [6]. Therefore, the major muscles affecting hip displacement are one-joint muscles, such as the adductor longus and brevis according to our study. The major surgical intervention of hip adductor spasticity in children with $\mathrm{CP}$ is to release the adductor longus and brevis muscles, which are one-joint muscles [33,34]. In addition, only the R1 angle of hip abduction with knee flexion, and not the R2, correlated with MP. The R2 angle of MTS means the shortening of muscles, but R1 angle of MTS includes dynamic spasticity of muscles $[6,12,13]$. This result may imply that reducing spasticity in one-joint hip adductor muscles can help to prevent hip subluxation in children with spastic $\mathrm{CP}$ [30,34,35].

Hip displacement, coxa valga, and excessive FA are common in children with spastic CP [3,4]. In previous reports, there were many arguments regarding correlations with hip deformities $[1,5,36,37]$. Some studies suggested that the hip displacement and FA were correlated [5,37]. Conversely, hip subluxation was reported not to correlate with FA, which was the same conclusion in our study $[1,36]$. However, the relationship between coxa valga and other hip and femoral deformities has not yet been reported. Our study revealed no correlation among all radiographic hip deformity parameters (Table 5). Further studies are still needed.

Many previous studies performed only cross-sectional analysis for hip and femoral deformities in children with $\mathrm{CP}$, which indicated that the investigators performed physical examinations and imaging studies at a similar time $[1,15,16,27,31,36,37]$. The strengths of the present study were that the effects of clinical parameters of young children were analyzed with imaging studies that were taken after more than 5 years of follow-up. Between 60 and 124 months, children in this study grew up and underwent rehabilitation under very different conditions, which could affect hip and femoral deformity in each child differently. Despite many possible confounding factors which could weaken the effects on bone deformations, our results showed strong associations between MP and dynamic spasticity of one-joint hip adductor muscles, and between FNS and dynamic spasticity and shortening of both one-joint and two-joint hip adductor muscles with high statistical significance.

In conclusion, our study indicated that hip displacement and coxa valga deformity were correlated with gross motor function impairment, dynamic spasticity, and shortening of hip adductor muscles; however, FA was not correlated with clinical parameters. Furthermore, radiographic hip and femoral deformity parameters were not correlated each other.

\section{CONFLICT OF INTEREST}

No potential conflict of interest relevant to this article was reported. 


\section{ACKNOWLEDGMENTS}

This study was supported by a Chyung Ki Lee research grant of Korean Academy of Rehabilitation Medicine for 2016.

\section{REFERENCES}

1. Chang CH, Wang YC, Ho PC, Hwang AW, Kao HK, Lee WC, et al. Determinants of hip displacement in children with cerebral palsy. Clin Orthop Relat Res 2015;473:3675-81.

2. Hagglund G, Lauge-Pedersen H, Wagner P. Characteristics of children with hip displacement in cerebral palsy. BMC Musculoskelet Disord 2007;8:101.

3. Soo B, Howard JJ, Boyd RN, Reid SM, Lanigan A, Wolfe $\mathrm{R}$, et al. Hip displacement in cerebral palsy. J Bone Joint Surg Am 2006;88:121-9.

4. Miller F. Cerebral palsy. New York: Springer; 2005. p. 523-666.

5. Sauser DD, Hewes RC, Root L. Hip changes in spastic cerebral palsy. AJR Am J Roentgenol 1986;146:121922.

6. Choi JY, Jung S, Rha DW, Park ES. Botulinum toxin type a injection for spastic equinovarus foot in children with spastic cerebral palsy: effects on gait and foot pressure distribution. Yonsei Med J 2016;57:496504.

7. Moreau M, Cook PC, Ashton B. Adductor and psoas release for subluxation of the hip in children with spastic cerebral palsy. J Pediatr Orthop 1995;15:672-6.

8. Chung CY, Lee KM, Park MS, Lee SH, Choi IH, Cho TJ. Validity and reliability of measuring femoral anteversion and neck-shaft angle in patients with cerebral palsy. J Bone Joint Surg Am 2010;92:1195-205.

9. Gilligan I, Chandraphak S, Mahakkanukrauh P. Femoral neck-shaft angle in humans: variation relating to climate, clothing, lifestyle, sex, age and side. J Anat 2013;223:133-51.

10. Boese CK, Frink M, Jostmeier J, Haneder S, Dargel J, Eysel P, et al. The modified femoral neck-shaft angle: age- and sex-dependent reference values and reliability analysis. Biomed Res Int 2016;2016:8645027.

11. Standring S. Gray's anatomy: the anatomical basis of clinical practice. 41th ed. Philadelphia: Elsevier Health Sciences; 2015. p. 1376-82.
12. Tardieu G, Shentoub S, Delarue R. Research on a technic for measurement of spasticity. Rev Neurol (Paris) 1954;91:143-4.

13. Boyd RN, Graham HK. Objective measurement of clinical findings in the use of botulinum toxin type A for the management of children with cerebral palsy. Eur J Neurol 1999;6(S4):S23-S35.

14. Martinsson C, Himmelmann K. Effect of weight-bearing in abduction and extension on hip stability in children with cerebral palsy. Pediatr Phys Ther 2011;23: 150-7.

15. Hoffer MM, Stein GA, Koffman M, Prietto M. Femoral varus-derotation osteotomy in spastic cerebral palsy. J Bone Joint Surg Am 1985;67:1229-35.

16. Lee KM, Kang JY, Chung CY, Kwon DG, Lee SH, Choi $\mathrm{IH}$, et al. Clinical relevance of valgus deformity of proximal femur in cerebral palsy. J Pediatr Orthop 2010;30:720-5.

17. Singh P, Joshua AM, Ganeshan S, Suresh S. Intra-rater reliability of the modified Tardieu scale to quantify spasticity in elbow flexors and ankle plantar flexors in adult stroke subjects. Ann Indian Acad Neurol 2011; 14:23-6.

18. Davids JR, Benfanti P, Blackhurst DW, Allen BL. Assessment of femoral anteversion in children with cerebral palsy: accuracy of the trochanteric prominence angle test. J Pediatr Orthop 2002;22:173-8.

19. Joseph B. Factors associated with internal hip rotation gait in patients with cerebral palsy. J Pediatr Orthop 2007;27:970.

20. Robin J, Graham HK, Selber P, Dobson F, Smith K, Baker R. Proximal femoral geometry in cerebral palsy: a population-based cross-sectional study. J Bone Joint Surg Br 2008;90:1372-9.

21. Ruwe PA, Gage JR, Ozonoff MB, DeLuca PA. Clinical determination of femoral anteversion. A comparison with established techniques. J Bone Joint Surg Am 1992;74:820-30.

22. Jiang N, Peng L, Al-Qwbani M, Xie GP, Yang QM, Chai Y, et al. Femoral version, neck-shaft angle, and acetabular anteversion in Chinese Han population: a retrospective analysis of 466 healthy adults. Medicine (Baltimore) 2015;94:e891.

23. Schutte LM, Hayden SW, Gage JR. Lengths of hamstrings and psoas muscles during crouch gait: effects of femoral anteversion. J Orthop Res 1997;15:615-21. 
24. Lamb DW, Pollock GA. Hip deformities in cerebral palsy and their treatment. Dev Med Child Neurol 1962;4:488-98.

25. Morrell DS, Pearson JM, Sauser DD. Progressive bone and joint abnormalities of the spine and lower extremities in cerebral palsy. Radiographics 2002;22:257-68.

26. Massaad A, Assi A, Bakouny Z, Sauret C, Khalil N, Skalli W, et al. Three-dimensional evaluation of skeletal deformities of the pelvis and lower limbs in ambulant children with cerebral palsy. Gait Posture 2016; 49:102-7.

27. Howard CB, McKibbin B, Williams LA, Mackie I. Factors affecting the incidence of hip dislocation in cerebral palsy. J Bone Joint Surg Br 1985;67:530-2.

28. Pountney T, Mandy A, Green E, Gard P. Management of hip dislocation with postural management. Child Care Health Dev 2002;28:179-85.

29. Pountney TE, Mandy A, Green E, Gard PR. Hip subluxation and dislocation in cerebral palsy - a prospective study on the effectiveness of postural management programmes. Physiother Res Int 2009;14:116-27.

30. Park ES, Rha DW, Lee WC, Sim EG. The effect of obturator nerve block on hip lateralization in low functioning children with spastic cerebral palsy. Yonsei
Med J 2014;55:191-6.

31. Larnert P, Risto O, Hagglund G, Wagner P. Hip displacement in relation to age and gross motor function in children with cerebral palsy. J Child Orthop 2014;8: 129-34.

32. Himmelmann K, Beckung E, Hagberg G, Uvebrant P. Gross and fine motor function and accompanying impairments in cerebral palsy. Dev Med Child Neurol 2006;48:417-23.

33. Givon U. Management of the spastic hip in cerebral palsy. Curr Opin Pediatr 2017;29:65-9.

34. Penner M, Xie WY, Binepal N, Switzer L, Fehlings D. Characteristics of pain in children and youth with cerebral palsy. Pediatrics 2013;132:e407-13.

35. Mall V, Heinen F, Siebel A, Bertram C, Hafkemeyer U, Wissel J, et al. Treatment of adductor spasticity with BTX-A in children with CP: a randomized, doubleblind, placebo-controlled study. Dev Med Child Neurol 2006;48:10-3.

36. Bleck EE. The hip in cerebral palsy. Orthop Clin North Am 1980;11:79-104.

37. Beals RK. Developmental changes in the femur and acetabulum in spastic paraplegia and diplegia. Dev Med Child Neurol 1969;11:303-13. 